\title{
Childhood mouth-breathing consequences at adult age: ventilatory function and quality of life
}

\author{
Consequências da respiração oral em adultos: \\ função ventilatória e qualidade de vida
}

\section{Jovana de Moura Milanesi ${ }^{[a]}$, Priscila Weber ${ }^{[b]}$, Luana Cristina Berwig ${ }^{[c]}$, Rodrigo Agne Ritzel ${ }^{[\mathrm{d}]}$, Ana Maria Toniolo da Silva ${ }^{[\mathrm{e}]}$, Eliane Castilhos Rodrigues Corrêa ${ }^{[\mathrm{f}]}$}

[a] PhD candidate, Universidade Federal de Santa Maria (UFSM), Programa de Pós-Graduação em Distúrbios da Comunicação Humana, Santa Maria, RS - Brazil, e-mail: jovanamil@yahoo.com.br

[b] MSc, Universidade Federal de Santa Maria (UFSM), Programa de Pós-Graduação em Distúrbios da Comunicação Humana, Santa Maria, RS - Brazil, e-mail: prifisio07@yahoo.com.br

[c] PhD candidate, Universidade Federal de Santa Maria (UFSM), Programa de Pós-Graduação em Distúrbios da Comunicação Humana, Santa Maria, RS - Brazil, e-mail: luanaberwig@gmail.com

[d] MSc, Universidade Federal de Santa Maria (UFSM), Programa de Pós-Graduação em Distúrbios da Comunicação Humana, Santa Maria, RS - Brazil, e-mail: rodrigoritzel@ymail.com

[e] PhD, professor, Universidade Federal de Santa Maria (UFSM), Programa de Pós-Graduação em Distúrbios da Comunicação Humana, Santa Maria, RS - Brazil, e-mail: amariatoniolo@gmail.com

[f] PhD, professor, Universidade Federal de Santa Maria (UFSM), Programa de Pós-Graduação em Distúrbios da Comunicação Humana, Santa Maria, RS - Brazil, e-mail: eliftrs@yahoo.com.br

\begin{abstract}
Introduction: Mouth breathing can affect the functions of the respiratory systems and quality of life. For this reason, children who grow up with this stimulus may have implications on physical and psychological aspects at adult age. Objective: To evaluate childhood mouth-breathing consequences for the ventilatory function and quality of life at adult age. Materials and methods: Prospective, observational and crosssectional study with 24 adults, between 18 and 30 years old, mouth breathers during childhood, comprised the childhood mouth-breathing group (CMB). The childhood nasal-breathing (CNB) group was composed of 20 adults of the same age, without history of respiratory disease during all their lives. Measurements of maximal respiratory pressures, peak expiratory flow and 6-minute walk test were assessed. In addition, all the volunteers answered the Short Form-36 questionnaire (SF-36). Results: The maximal inspiratory ( $p=$
\end{abstract}


$0.001)$ and expiratory $(p=0.000)$ pressures as well as the distance in the walk test $(p=0.003)$ were lower in the COB. The COB also presented lower score in the General Health domain of the SF-36 Questionnaire ( $p=$ 0.002). Conclusion: Childhood mouth-breathing yields consequences for the ventilatory function at adult age, with lower respiratory muscle strength and functional exercise capacity. Conversely, the quality of life was little affected by the mouth breathing in this study.

Keywords: Mouth breathing. Quality of life. Respiratory muscles. Exercise tolerance.

\section{Resumo}

Introdução: A respiração oral pode afetar o sistema respiratório e a qualidade de vida e, crianças que crescem com este estímulo podem trazer implicações em aspectos físicos e psicológicos na idade adulta. Objetivo: Avaliar as consequências da respiração oral na infância na função ventilatória e qualidade de vida de adultos. Materiais e métodos: Estudo prospectivo, observacional e transversal com 24 adultos, entre 18 e 30 anos, respiradores orais na infância (ROI). O grupo respiradores nasais na infância (RNI) foi composto por 20 adultos da mesma idade, sem história de doença respiratória até o momento. Foram avaliadas as medidas das pressões respiratórias máximas, pico de fluxo expiratório e teste de caminhada de 6 minutos (TC6). Todos os voluntários responderam o questionário de qualidade de vida Short Form-36 (SF-36). Resultados: As pressões inspiratória ( $p=0,001)$ e expiratória ( $p=0,000)$ máximas e a distância percorrida no TC6' $(p=0,003)$ foram menores no grupo ROI. O grupo ROI também apresentou um escore menor no domínio Estado Geral de Saúde do questionário SF-36 ( $p=0$,002). Conclusão: A respiração oral na infância provoca consequências na função ventilatória na idade adulta, com diminuição na força muscular respiratória e na capacidade funcional ao exercício. Porém, esta trouxe pequena implicação na qualidade de vida dos sujeitos desta pesquisa.

Palavras-chave: Respiração bucal. Qualidade de vida. Músculos respiratórios. Tolerância ao exercício.

\section{Introduction}

As people age, adults have nasal respiratory mode, as neonates (1). Mouth-breathing may become predominant in childhood, raising consequences for the respiratory system and life quality $(2,3)$. This may occur due to tonsillar hypertrophy, nasal mucous membrane allergic edema and septal deviation, that increase the respiratory airway resistance $(4,5,6$, 7). It is possible that the severity of the obstruction has higher impact in the consequences of the mouth breathing, regardless it's a etiology, however few studies demonstrated this $(8,9)$.

Breathing is a process that involves neural, chemical and muscular components and has as the main agents the diaphragm, intercostal and abdominal muscles $(10,11)$. Mouth-breathing children present abnormal use of the breathing muscles, what can be associated with the muscular fatigue (10). Besides, studies have shown a decrease of the maximal inspiratory pressure and thoracic mobility in mouth breathing children $(2,7)$.
One study found in the literature evaluated the lung function to verify the effectiveness of the physiotherapy intervention consisted by postural correction and respiratory reeducation with stretching of inspiratory accessory muscles and abdominal muscles reinforcement (12). The authors observed the diaphragmatic ventilatory pattern in $43 \%$ and $86 \%$ and, normal lung function in $21 \%$ and $57 \%$ of children, before and after treatment, respectively. The results confirmed that there are changes in mouth breathers' lung function that should be treated and, periodic evaluations were suggested due to the risk of obstructive condition recurrence (12).

Asthma, rhinitis and oral breathing provoke not only respiratory, but also behavioral and functional impairments that affect directly the quality of life (13). There is a negative impact on learning, cognitive ability, memory and psychosocial relationships (3). Neiva et al. (14) did not find differences regarding the quality of life assessed in mouth and nasal breathing children. Although, the quality of life assessment is too subjective, it is essential for the health 
promotion practice, mainly when related to chronic diseases (15).

Considering that mouth-breathing alterations can be progressive and the therapeutic intervention during childhood could not be enough addressed to all these changes (16), it is important to verify their consequences at adult age. However, this respiratory mode impact is still not much investigated in adulthood.

The purpose of this research is to compare the maximal respiratory pressures, peak expiratory flow, inspiratory capacity, the functional exercise capacity and the quality of life of adults with clinical diagnose of mouth- breathing children and the healthy ones.

\section{Materials and methods}

The research was carried out in the Federal University of Santa Maria and is part of a larger project entitled "Characterization, evaluation and integrated therapy of orofacial motor disorders and body posture". It was approved by Ethics Committee of Federal University of Santa Maria, under the protocol number 0220.0.243.000.08. All volunteers agreed to take part in the study by signing a written consent form.

\section{Subjects}

Data were collected from mouth breathing children's records, evaluated in the Service of Speech Therapy Assistance of Federal University of Santa Maria from 1998 to 2003. The inclusion criteria were: age between 18 and 30 years old; both genders; clinical manifestations of mouth breathing in childhood, treated or not, such as: snoring, drooling on the pillow, mouth open most part of the day and/or during sleep, according the patients' record. Additionally, the presence of etiological factors, such as allergic rhinitis, enlarged adenoids or tonsils, obstructive deviation of the nasal septum and nasal polypus was considered. Thereby, the childhood mouth-breathing group (CMB) was composed of 24 adults, clinically diagnosed with mouth-breathing during childhood by speech therapy staff.

The childhood nasal breathing group (CNB) was composed of 20 adults of the same age, without history of respiratory disease during all their lives. The inclusion criteria considered was: absence of signs and symptoms of allergic rhinitis, enlarged adenoids or tonsils, obstructive deviation of the nasal septum and nasal polypus; absence of asthma and other obstructive or restrictive lung disease. Data were collected through a questionnaire containing complete history on the presence of respiratory illnesses in childhood and adolescence.

Subjects with signs of neurological problems, craniofacial malformation and cognitive disturbances were excluded.

\section{Procedures}

An anamnesis and quality of life assessment by the Medical Outcomes Study 36-Item Short-Form Health Survey (SF-36) were carried out. This questionnaire is composed of 36 items and 8 different domains, such as: functional capacity, physical aspects, pain, health general status, vitality, social aspects, emotional aspects and mental health. The score is from 0 (worse health status) to 100 (best health status) for each domain. The volunteers were instructed to carefully read the questionnaire and answer questions addressing to the research if necessary.

Assessments of inspiratory (IMP) and expiratory (EMP) maximal pressure, peak expiratory flow, inspiratory capacity and functional exercise capacity measured by the Six-minute Walk Test (6MWT) were carried out in both groups.

The respiratory pressures were measured in seated position, by a manometer (Globalmed ${ }^{\circledR}$ ) with a scale ranging from -150 to $150 \mathrm{cmH}_{2} \mathrm{O}$ adapted to a plastic mouthpiece with $2 \mathrm{~mm}$ opening to prevent oral pressure (17). The IMP was obtained during a forced inspiration from residual volume and the EMP was obtained from the total lung capacity. Due to the variability related to gender and age, a percentage of the predicted value was calculated (18).

The peak of expiratory flow was measured by portable equipment (Assess ${ }^{\circledR}$ ) and the volunteer was oriented to breathe deeply and after, exhale as fast and strong as possible through the mouthpiece. The mean value of three measures was considered and the difference among them could not be more than 40 $\mathrm{l} / \mathrm{min}$. The predictive value percentage for Brazilian people was calculated by Pereira (19), considering gender, height and age.

A volumetric incentive spirometer with a scale from 0 to $5000 \mathrm{ml}$ (Voldyne ${ }^{\circledR}$ ) measured the inspiratory 
capacity, while the volunteer inspired at maximal effort from normal expiration, in seated position. The mean value of three measures was also considered.

The six-minute walk test was carried out according to the American Thoracic Society guidelines (20): a six-minute walk in a closed and linear passage, on a smooth and 24 meter-length floor. All the assessments were performed at the same location and climatic conditions. The measures of respiratory rate, heart rate and oxygen saturation were verified by a pulse oximeter and a chronometer. The performance of each volunteer was expressed by the total distance walked in meters during six minutes.

Otorhinolaryngologic and speech therapy assessments were carried out in order to characterize the current respiratory mode and obstructive problems of the study group.

\section{Data analysis}

The data were analyzed by the STATISTCA 9.0 (Statistica for Windows - release 9.0 Stat Soft) and PASW 17.0 software. The Lilliefors test verified the normal distribution of the variables. The differences between the groups were analyzed by the Student $t$ and Chi-square tests for age and gender, respectively. The comparison between the variables of the study and control groups was carried out by the Student $t$ test. The U Mann-Whitney test analyzed the results of the quality of life questionnaire. The significance level was set at $5 \%(\mathrm{p}<0.05)$.

\section{Results}

The evaluation procedures were carried out in 44 subjects, 24 of the CMB, 9 men and 15 women and, 20 of the CNB, 3 men and 17 women. There was no difference between the groups regarding gender $(\mathrm{p}=$ 0.264 ). The groups were also uniform concerning the age and Body Mass Index (BMI) (Table 1).

The CMB individuals previously underwent surgical treatment (46\%), adenoidectomy and/or amygdalectomy in nine patients (38\%) and septoplasty in two $(8 \%)$. They were also treated with speech therapy (54\%), orthodontic treatment (67\%) and postural physical therapy (17\%). Only one of the 24 subjects did not receive any type of treatment.

According to the otorhinolaryngologic and speech therapy assessments, the oral and oronasal respiratory mode was still present in $30 \%$ and $55 \%$ of the participants in the CMB group, respectively, and only $15 \%$ of them presented nasal breathing.

The maximal inspiratory and expiratory pressures were lower in the $\mathrm{CMB}$ compared to the $\mathrm{CNB}$ (Table 1).

During the Six-minute walk test, all volunteers from both groups presented oxygen saturation from 97 to $100 \%$ before and after the test. The distance walked was significant shorter $(\mathrm{p}=0.003)$ in the CMB compared to the CNB (Table 2).

The results of the eight domain of the SF-36 questionnaire demonstrated a lower score in the general health status domain in the CMB (Table 3). Out of 24 CMB volunteers, 20 fulfilled this instrument.

Table 1 - Comparison of demographic and respiratory parameters between groups

\begin{tabular}{lccc}
\hline & COB $(\mathbf{n}=\mathbf{2 4})$ Mean \pm SD & CNB $(\mathbf{n}=\mathbf{2 0})$ Mean \pm SD & $p$ \\
\hline AGE (years) & $22.62 \pm 3.09$ & $24.6 \pm 1.41$ & 0.059 \\
BMI (Kg/cm²) & $22.52 \pm 3.74$ & $21.89 \pm 2.27$ & 0.511 \\
$\%$ IMP & $56 \% \pm 18 \%$ & $74 \% \pm 15 \%$ & $0.001^{*}$ \\
\%EMP & $66 \% \pm 10 \%$ & $84 \% \pm 14 \%$ & $0.000^{*}$ \\
PEF (I/min) & $407 \pm 145$ & $382 \pm 73$ & 0.495 \\
\%PEF & $78 \% \pm 21 \%$ & $81 \% \pm 13 \%$ & 0.472 \\
IC (I) & $2769 \pm 1093$ & $2967 \pm 950$ & 0.529 \\
\hline
\end{tabular}

Note: COB: childhood oral breathing; CNB: childhood nasal breathing; n: sample components; SD: standard deviation; BMI: body mass index; $\mathrm{Kg} / \mathrm{cm}^{2}$ : kilogram per square centimeters; IMP: inspiratory maximal pressure; EMP: expiratory maximal pressure; PEF: peak expiratory flow; I/min: liters per minute; IC: inspiratory capacity; I: liters. * $p<0.05-T$ Student Test.

Source: Research data. 
Table 2 - Comparison of the obtained results in the 6 MWT between groups

\begin{tabular}{lccc}
\hline \multicolumn{1}{c}{ Variables } & COB $(\mathrm{n}=\mathbf{2 4})$ Mean \pm SD & CNB $(\mathrm{n}=\mathbf{2 0})$ Mean \pm SD & $p$ \\
\hline HRi (beats/min) & $77 \pm 11$ & $72 \pm 12$ & 0.143 \\
HRf (beats/min) & $104 \pm 20$ & $106 \pm 24$ & 0.858 \\
RRi (respiration/min) & $17 \pm 4$ & $17 \pm 4$ & 0.831 \\
RRf (respiration/min) & $21 \pm 4$ & $23 \pm 7$ & 0.371 \\
Distance walked $(\mathrm{m})$ & $572 \pm 51$ & $615 \pm 35$ & $0.003^{*}$ \\
\hline
\end{tabular}

Note: MWT: six minute walk test; COB: childhood oral breathing; CNB: childhood nasal breathing; n: sample components; SD: standard deviation; HRi: initial heart rate; HRf: final heart rate; RRi: initial respiratory rate; RRf: final respiratory rate; m: meters. ${ }^{*} p<0.05-\mathrm{T}$ Student Test.

Source: Research data.

Table 3 - Comparison of the obtained scores for the eight domains of quality of life questionnaire between groups

\begin{tabular}{lccc}
\hline Domains & COB $(\mathbf{n}=\mathbf{2 0})$ Score $^{\star *}$ & CNB $(\mathbf{n}=20)$ Score $^{\star \star}$ & $p$ \\
\hline Functional Capacity & $93 \pm 9$ & $92 \pm 9$ & 0.818 \\
Physical Aspects & $81 \pm 32$ & $88 \pm 29$ & 0.457 \\
Pain & $76 \pm 17$ & $75 \pm 21$ & 0.776 \\
Health General Status & $69 \pm 14$ & $83 \pm 19$ & $0.002^{*}$ \\
Vitality & $63 \pm 20$ & $68 \pm 17$ & 0.387 \\
Social Aspects & $83 \pm 20$ & $80 \pm 22$ & 0.776 \\
Emotional Aspects & $59 \pm 41$ & $76 \pm 34$ & 0.223 \\
Mental Health & $72 \pm 22$ & $73 \pm 18$ & 0.957 \\
\hline
\end{tabular}

Note: COB: childhood oral breathing; CNB: childhood nasal breathing; n: sample components. ${ }^{*} p<0.05$ - U Test. ${ }^{* *}$ Values expressed as mean and standard deviation.

Source: Research data.

\section{Discussion}

Mouth-breathing (MB) is a substitute respiratory mode and consists of a mechanically incorrect form of respiration. It has a multifactor etiology and multiple consequences $(6,14,21)$. However, studies describing the features of the respiratory system and the quality of life of adults - diagnosed as mouth breathers in childhood - were not found.

Despite the oral breathing participants received treatment during childhood, a high percentage of them currently present oral and oronasal breathing (85\%), suggesting that surgical treatment and short-term results of other treatments seem not to be enough to avoid long-term consequences and to reestablish the nasal respiratory mode. Therefore, the results obtained in these subjects should be attributed not only the childhood mouth breathing but also their current respiratory mode, that is, oral or oronasal.

It should be reinforced that physical therapy was the least treatment received by the participants. The physical therapy intervention consisted by postural correction and respiratory reeducation with stretching of inspiratory accessory muscles and abdominal muscles reinforcement may contribute to reduce the work of cervical muscles during the inspiration. Thereby, decreasing the respiratory effort by the 
improvement of the diaphragmatic ventilatory pattern (12). A Physical Therapy Program with stretching and strengthening exercises on the SwissBall, in combination with breathing exercises and directed movements to restore postural alignment, through stretching of the anterior muscles and strengthening of the posterior muscles of the trunk decreased the recruitment of the inspiratory accessory muscles during nasal inspiration (22).

Ribeiro et al. (23) found an increase of the acessory inspiratory muscles' activity, that is, sternocleidomastoid and upper trapezius, in mouth breathing children compared to the nasal ones during relaxed position. Such results were attributed to the body posture and consequent muscular unbalance. A higher inspiratory effort in mouth breathers demands the accessory inspiratory muscles recruitment probably due to the lower inspiratory strength.

In the present research, adults who were mouthbreathing diagnosed during childhood, presented lower respiratory maximal pressures compared to the control group. These results were similar to Okuro et al. (24) that also verified lower values of the respiratory maximal pressures in a group of mouth breathing children. These authors suggest that this decrease in the respiratory muscular strength may be related to the head posture changes consequential to the mouth breathing. A misaligned posture may affect respiratory muscles' length, reducing its strength. A more forward head posture was found by Milanesi et al. (25) in adults diagnosed with mouth breathing during childhood, suggesting that the alterations resulting from this breathing mode may perpetuate at adult age. So it seems that oral breathing leads to an abnormal use of the respiratory muscles and in the presence of an upper airway obstruction; breathing becomes difficult which can result in fatigue of these muscles (13).

It should be clarified that, in this research, both groups presented values of the maximal respiratory pressures lower than the predictive values (18). Even so, these values were significantly lower in the CMB compared to the CNB.

There was no difference between groups in the peak of expiratory flow and the inspiratory capacity. A greater respiratory work seems to be more evident when the mouth breathing is associated with respiratory diseases as asthma or allergic rhinitis (26). The peak of expiratory flow assessment is better recommended to the clinical and functional control of asthma symptoms (27). The occurrence of asthma was not reported by the subjects of the present study, what may explain the lack of difference in the peak of expiratory flow values between the groups.

There was no difference in the respiratory rate, heart rate and the oxygen saturation before and after the walk test in both groups. A shorter walk distance was verified in the CMB. The mean walked distance was $572 \pm 51$ meters in the CMB and 615 \pm 35 meters in the CNB. This finding is according to study who found a mean walked distance of 615,77 $\pm 83,87$ meters for 21 sedentary healthy subjects of both genders, 20 to 40 years old (28). The higher the airflow limitation is the lower the tolerance to physical exertion (29).

It must be pointed that mouth breathing is frequently associated with asthma and these ventilatory changes could be found in asthmatic subjects. Hallani et al. (30) have stated that an increase in nasal resistance and sensitivity to nasal loading may increase the susceptibility of asthmatic subjects to switch from nasal to oral breathing. In the present study, the subjects did not present previous or current history of asthma, what excludes this confounding factor in the modifications of the ventilatory function observed in the CMB.

Due to physical and psychological changes, the mouth breathing negatively influences the quality of life (14). However, these authors obtained similar results in the quality of life assessed by the AUQEI questionnaire (Autoquestionnaire Qualité de Vie Efant Imagine) in mouth and nasal breathing children. The authors justified such results because mouth-breathing is not realized by the child or family member as a limiting medical condition. The SF-36 questionnaire is the recommended instrument to evaluate the health status in adults with allergic rhinitis (31). Additionally, despite the learning, cognition and the professional performance impairments, health professionals do not recognize the impact of the allergic rhinitis and mouth breathing on quality of life (32).

In the present research, only the scores of the general health status domain in the SF-36 questionnaire were lower in the CMB. One study evaluated the impact of the asthma and rhinitis on women and men's quality of life obtaining worse scores in all domains of the SF-36 questionnaire in women compared to men from 16 to 49 years old. Additionally, patients with rhinitis from both sexes presented worse scores in most domains compared to a control group (33). 
Conversely, it was related that diseases as asthma, rhinitis and mouth breathing produce not only respiratory, but also behavioral and functional impairments that affect directly the quality of life (32).

These findings demonstrated the necessity of interdisciplinary intervention, including the respiratory muscular retraining and improvement of the exercise tolerance, not only in childhood but also throughout adult age. Further studies are necessary to investigate the same and other aspects related to the mouth breathing implications.

\section{Conclusion}

As a conclusion, this study presents important evidences that childhood mouth-breathing yields consequences for the ventilatory function at adult age, with lower respiratory muscle strength and functional exercise capacity. On the other hand, the quality of life was little affected by the mouth breathing in this study.

Considering the lack of published studies regarding mouth breathing consequences for several structures and functions of the human body, it is essential to investigate interdisciplinary approach outcomes as well as have a long term follow-up.

\section{Acknowledgement}

The authors thank Katia Sebalhos for the English review and professor Anaelena B. Moraes for the statistical data analysis.

\section{References}

1. Ward KA, Nicholls DP, Stanford CF. The prevalence of preferential nasal breathing in adults. Respir Med. 1993;87(4):296-7.

2. Pires MG, Di Francesco RC, Grumach AS, Mello Junior JF. Evaluation of inspiratory pressure in children with enlarged tonsils and adenoids. Braz J Otorhinolaryngol. 2005;71(5):598-601.

3. Campanha SMA, Freire LMS, Fontes MJF. Impact of asthma, allergic rhinitis and mouth breathing in life quality of children and adolescents. Rev CEFAC. 2008;10(4):513-9.
4. D’Ascanio L, Lancione S, Pompa G, Rebuffini E, Mansi $\mathrm{N}$, Manzini M. Craniofacial growth in children with nasal septum deviation: a cephalometric comparative study. Int J Pediatr Otorhinolarygol. 2010;74:1180-3.

5. Kawashima S, Peltomaki T, Sakata H, Mori K, Happonen RP, Ronning O. Craniofacial morphology in preschool children with sleep related breathing disorder and hypertrophy of tonsils. Acta Paediatr. 2002;91(1):71-7.

6. Branco A, Ferrari GF, Weber SAT. Orofacial alterations in allergic diseases of the airways. Rev Paul Pediatr. 2007;25(3):266-70.

7. Pires MG, Di Francesco RC, Mello Junior JF, Grumach AS. Chest modification secondary to the enlarged tonsils and adenoids. Arq Int Otorrinolaringol. 2007; 11(2):99-105.

8. Boton LM, Silva AMT, Bolzan GP, Corrêa ECR, Busanello AR. Electromyographic study on facial muscles of nasal breathers, obstructive and vicious oral breathers. Rev CEFAC. 2011;13(1):27-34.

9. Bolzan GP, Silva AMT, Boton LM, Corrêa ECR. Study of anthropometric measurements and orofacial proportions of nasal-and mouth-breathing children from different etiologies. Rev Soc Bras Fonoaudiol. 2011;16(1):85-91

10. Kendall FP, McCreary EK, Provance PG, Rod MM. Músculos: provas e funções: com postura e dor. São Paulo: Manole; 2007.

11. Ratnovsky A, Elad D, Halpern P. Mechanics of respiratory muscles. Respir Physiol Neurobiol. 2008;163(1-3):82-9.

12. Ribeiro EC, Soares LM. Spirometric evaluation of children with mouth breathing syndrome before and after physiotherapy treatment. Fisioter Bras. 2003; 4(3):163-7.

13. Banzatto MGP, Grumach AS, Mello Junior JF, Di Francesco RC. Adenotonsillectomy improves the strength of respiratory muscles in children with upper airway obstruction. Int J Pediatr Otorhinolarygol. 2010;74(8):860-3.

14. Neiva PD, Kirkwood RN, Godinho R. Orientation and position of head posture, scapula and thoracic spine in mouth-breathing children. Int J Pediatr Otorhinolarygol. 2009;73(2):227-36. 
15. Guyatt GH, Feeny DH, Patrick DL. Measuring healthrelated quality of life. Ann Intern Med. 1993; 118(8):622-9.

16. Yi LC, Jardim JR, Inoue DP, Pignatari SSN. The relationship between excursion of the diaphragm and curvatures of the spinal column in mouth breathing children. J Pediatr (Rio J). 2008;84(2):171-7.

17. American Thoracic Society/European Respiratory Society. ATS/ERS Statement on respiratory muscle testing. Am J Respir Crit Care Med. 2002;166(4):518-624.

18. Neder JA, Andreoni S, Lerario MC, Nery LE. Reference values for lung function tests. II. Maximal respiratory pressures and voluntary ventilation. Braz J Med Biol Res. 1999;32(6):719-27.

19. Pereira CAC. Espirometria. J Pneumol. 2002;28(3): 29-32.

20. ATS Committee on Proficiency Standarts for Clinical Pulmonary Function Laboratories. ATS statement: guidelines for the six-minute walk test. Am J Respir Crit Care Med. 2002;166(1):111-7.

21. Cattoni DM, Fernandes FDM, Di Francesco RC, Latorre MRDO. Quantitative evaluation of the orofacial morphology: anthropometric measurements in healthy and mouth-breathing children. Int J Orofacial Myology. 2009;35:44-54.

22. Corrêa ECR, Bérzin F. Mouth breathing syndrome: cervical muscles recruitment during nasal inspiration before and after respiratory and postural exercises on Swiss Ball. Int J Pediatr Otorhinolaryngol. 2008;72:1335-43.

23. Ribeiro EC, Marchiori SC, Silva AM. Electromyographic muscle EMG activity in mouth and nasal breathing children. J Craniomandibular Pract. 2004;22(2):145-50.

24. Okuro RT, Morcillo AM, Sakano E, Schivinski CIS, Ribeiro MAGO, Ribeiro JD. Exercise capacity, respiratory mechanics and posture in mouth breathers. Braz J Otorhinolaryngol. 2011;77 (5):656-62.

25. Milanesi JM, Borin G, Corrêa EC, Silva AM, Bortoluzzi DC, Souza JA. Impact of the mouth breathing occurred during childhood in the adult age: biophotogrammetric postural analysis. Int J Pediatr Otorhinolaryngol. 2011;75(8):999-1004.
26. Koh YY, Kim CK. The development of asthma in patients with allergic rhinitis. Curr Opin Allergy Clin Immunol. 2003;3(3):159-64.

27. Takara GN, Ruas G, Pessoa BV, Jamami LK, Di Lorenzo VAB, Jamami M. Comparison of five portable peak flow meters. Clinics. 2010;65(5):469-74.

28. Pires SR, Oliveira AC, Parreira PF, Britto RR. Six-minute walk test at different ages and body mass index. Rev Bras Fisioter. 2007;11(2):147-51.

29. Marino DM, Marrara KT, Di Lorenzo VAP, Jamami M. Six-minute gait test in chronic obstructive pulmonary disease with different degrees of obstruction. Rev Bras Med Esporte. 2007;13(3):103-6.

30. Hallani M, Wheatley JR, Amis TC. Initiating oral breathing in response to nasal loading: asthmatics versus healthy subjects. Eur Respir J. 2008;31:800-6.

31. Majani G, Baiardini I, Giardini A, Senna GE, Minale P, D'Ulisses S, et al. Health-related quality of life assessment in young adults with seasonal allergic rhinitis. Allergy. 2001;56(4):313-7.

32. Camelo-Nunes IC, Solé D. Allergic rhinitis: indicators of quality of life. J Bras Pneumol. 2010;36(1):124-33.

33. Larrson U, Taft C, Karlsson J, Sullivan M. Gender and age differences in the relative burden of rhinitis and asthma on health-related quality of life - A Swedish population study. Respir Med. 2007;101(6):1291-8.

Received: 06/22/2013 Recebido: 22/06/2013

Approved: $12 / 03 / 2013$ Aprovado: 03/12/2013 